\title{
Effectiveness of Tarantula Cubensis Extract in the Treatment of Bovine Papillomatosis
}

\author{
M. V. Swamy Babu ${ }^{1}$, P. Veena ${ }^{1 *}$, R. V. Suresh Kumar ${ }^{1}$, \\ P. Amaravathi ${ }^{2}$ and G. Vani $^{1}$ \\ ${ }^{1}$ Department of Veterinary Surgery and Radiology, College of Veterinary Science, \\ Tirupati, A P, India \\ ${ }^{2}$ SLDL: Dept of Veterinary Pathology, College of Veterinary Science, Tirupati. A P, India \\ *Corresponding author
}

\section{A B S T R A C T}

\section{Keywords}

Bovine papilloma, Tarantula cubensis extract

\section{Article Info}

Accepted:

05 April 2020

Available Online:

10 May 2020
The present clinical study was conducted to study the efficacy of tarantula cubensis extract on bovine papillomatosis. Among total of 3812 cattle presented to the clinic, 52 cattle were having papillomas. The animals were treated with $10 \mathrm{ml}$ of tarantula cubensis extract subcutaneously at weekly once for two weeks. Tarantula cubensis extract was found to be efficacious in the treatment of bovine papillomatosis with no occurrence for a period of 6 months.

\section{Introduction}

The bovine papillomatosis is an infectious, contagious and neoplastic disease characterized by the presence of multiple, benign tumours (Papillomas) that can regress spontaneously or progress to malignant neoplasms. It is instigated by oncogenic Bovine papilloma viruses (BPV) which are non-enveloped icosahedral viruses, $50-55 \mathrm{~nm}$ in diameter, with a circular, double stranded
DNA genome ranging from 7.4 to $8.6 \mathrm{~kb}$ (Somvanshi, 2011). It can be exhibited as benign nodular lesions, finger like projections or cauliflower like small growths on the skin arising from stratified squamous epithelium that may appear solitary or in multiples.

This disease has got great economic importance since the lesions located on udder and teats hinder milking there by farmers suffers with economic losses. 
Papillomatous growths reduce skin value. Sometimes it may be complicated with other bacterial infections, maggots infestations etc. Lesions located on eyes, eye lids obstruct vision and growths surrounding oral cavity affect feed intake, mastication leads to anorexia and weight loss. Genital warts show effect on reproduction. Although many different methods are used to treat Papillomatosis, many of them are difficult and cumbersome to implement. For this reason the object of this study was to examine the effectiveness of tarantula cubensis extract in the treatment of bovine papilloma.

\section{Materials and Methods}

The study was conducted on clinical cases presented to college of veterinary science, Tirupati. The protocol was approved by Animal Experiments Local Ethics Committee. The animals were treated with $10 \mathrm{ml}$ of tarantula cubensis extract subcutaneously at weekly once for two weeks. The initiation of treatment was considered as day 0 and the animals were monitored every 15 days up to 90 days and the healing process of the papilloma was recorded.

\section{Results and Discussion}

A decrease in size and drying and shrinking of the papillomas were observed in all the animals after 15 days of treatment. The

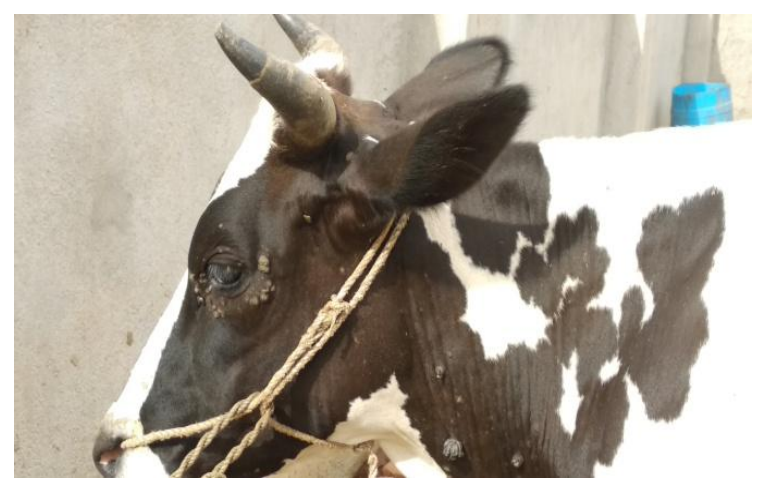

Before treatment efficacy of the treatment was $100 \%$ with no recurrence for a period of 6 months. All animals recovered completely with no adverse reactions. The tarantula cubensis extract was very effective in both sessile and pedunculated papillomas (Fig 1).

The use of alternative treatments is expanding in human medicine, but information about the extension of such practices to veterinary medicine is limited, as good records of the use of these treatments did not exist. The increasing and effective use of homoeopathy in veterinary medicine without side effects demonstrates that many veterinarians apply this treatment as a natural stimulator for a self-healing mechanism in animals. Homoeopathy is the selection of a substance to cure a disease by knowing that some substances could cause the symptoms seen in a patient (Gultekin et al., 2015).

The extract of tarantula cubensis is a homeopathic drug used widely in veterinary medicine. It is effective through the spider venom it contains. Tarantula cubensis extract is used to treat foot and hoof rot. Tarantula cubensis extract stimulate the absorption and demarcation of many types of ulcers and necrosis as well as treating mammary gland tumors and proliferative cases in animals (Gultiken and Vural 2007 and Gultiken et al., 2015 in canine mammary tumors, Icen et al., 2011 in canine oral papillomatosis).

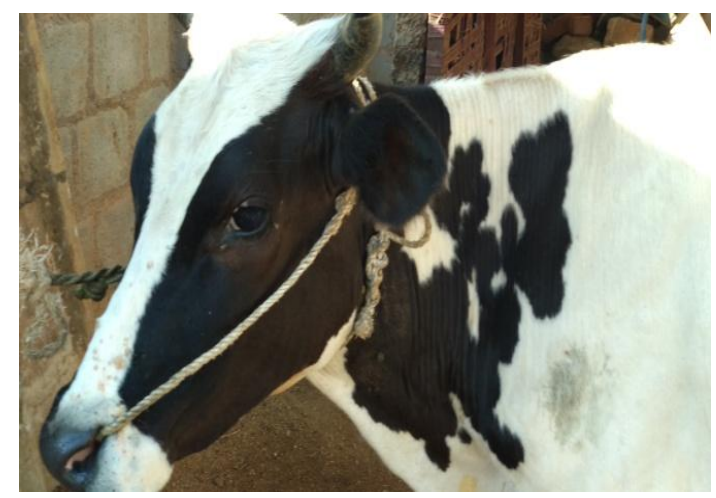

After treatment 

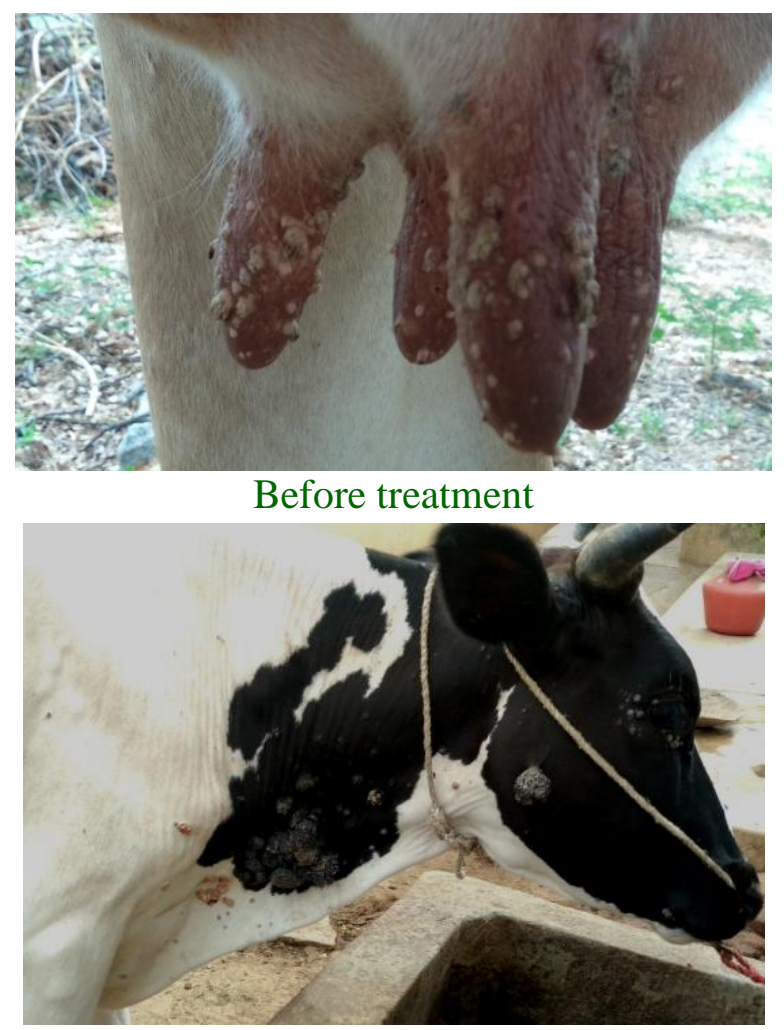

Before treatment

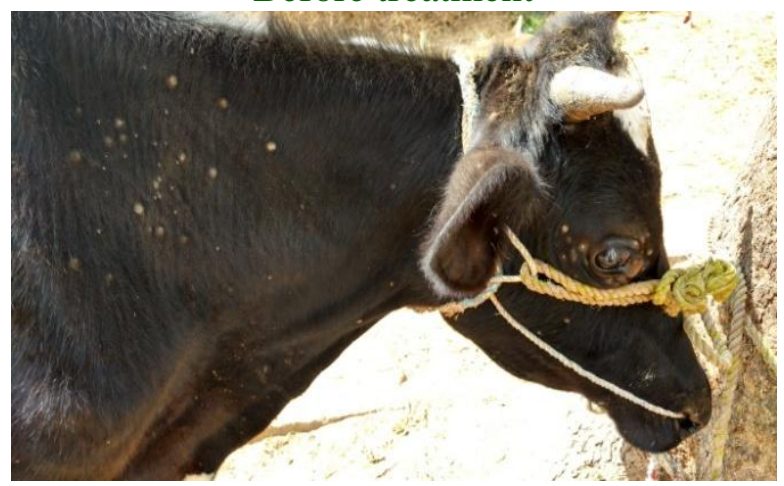

Before treatment

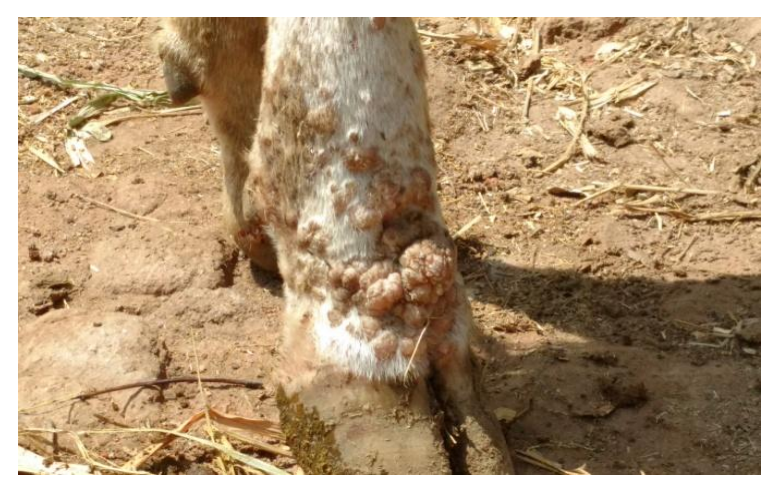

Before treatment

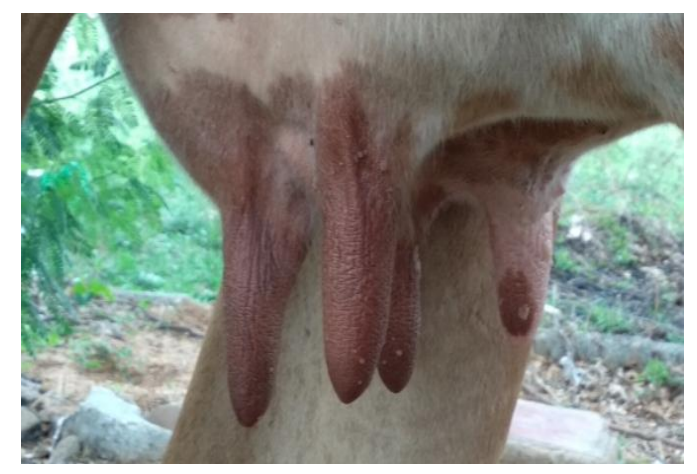

After treatment

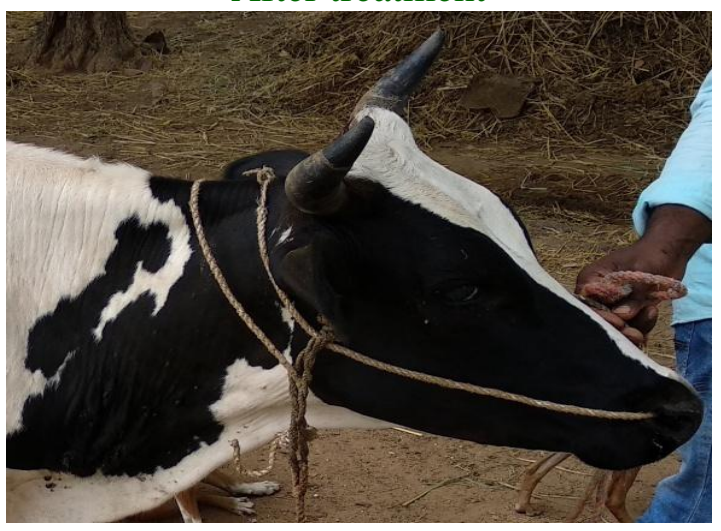

After treatment

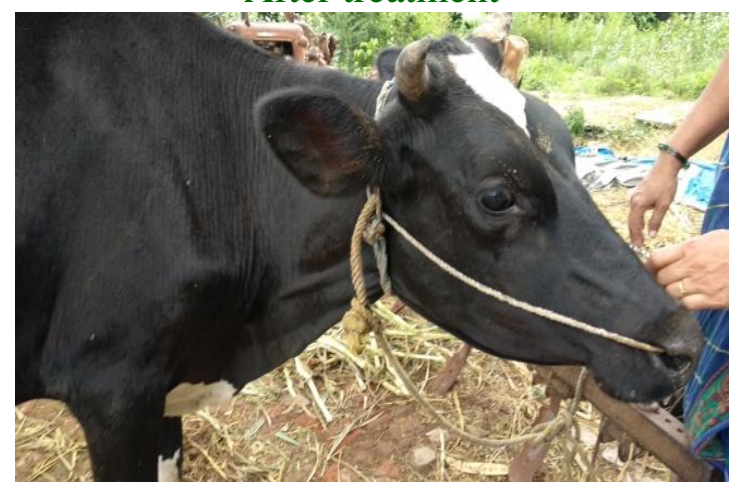

After treatment

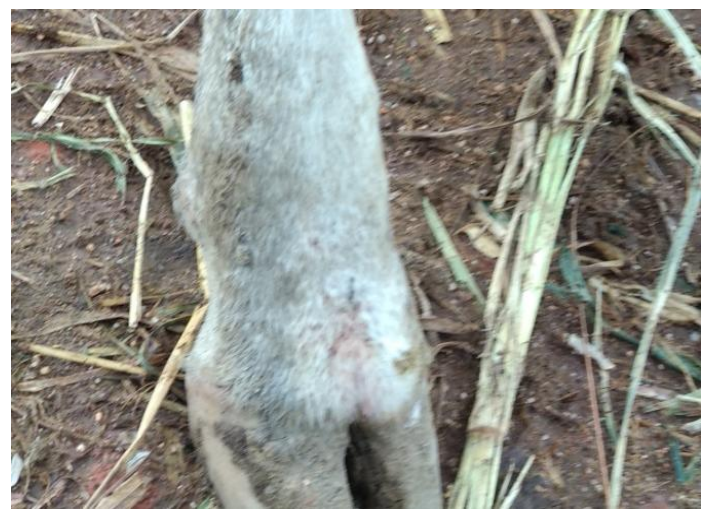

After treatment 
In this study, tarantula cubensis extract was found to be effective in decreasing clinical lesions in bovine papillomatosis and the post treatment observations for 6 months. Papillomas regression was verified after the second week evidenced by papillomas necrosis, detachment and fall. There was no recurrence in any animal, with no adverse reaction. Although the mechanism of action of tarantula cubensis extract was not completely clear, it is thought to stimulate the defence mechanism of the body to aid spontaneous remission (Cam et al., 2007). Similar findings were reported by Paksoy et al., (2015) who used tarantula cubensis extract for the treatment of bovine teat papillomatosis.

\section{References}

Cam Y, Kibar M, Atasever A, Atalay O and Beyaz L 2007 Efficacy of levamisole and tarantula cubensis venom for the treatment of bovine cutaneous papillomatosis. Veterinary Record 160:486-488.

Gültiken N and Vural M R 2007 The effect of tarantula cubensis extract applied in pre and post-operative period of canine mammary tumors. Journal of Istanbul Veterinary Sciences 2:13-23.

Gultiken N, Guvenc T, Kaya D, Agaoglu A R, Ay S S, Kucukaslan I, Emre B, Findik M, Somi S and Aslan S 2015 Tarantula cubensis extract alters the degree of apoptosis and mitosis in canine mammary adenocarcinomas. Journal of Istanbul Veterinary Science 16(2):213-219.

Icen $\mathrm{H}$, Sekin S, Simsek A, Kochan A and Tunik S 2011 The efficacy of tarantula cubensis extract(Theranekron) in treatment of canine oral papilloma. Asian Journal of Animal and Veterinary Advances 6(7): 744-749

Paksoy Z, Gulesci N, Kandemir F M and Dinçel G C 2015 Effectiveness of levamisole and tarantula cubensis extract in the treatment of teat papillomatosis of cows. Indian Journal of Animal Research 49(5):704-708.

Somvanshi R 2011 Papillomatosis in buffaloes: A less-Known Disease. Transboundary and Emerging Diseases 58:327-332.

\section{How to cite this article:}

Swamy Babu. M. V., P. Veena, R. V. Suresh Kumar, P. Amaravathi and Vani. G. 2020. Effectiveness of Tarantula Cubensis Extract in the Treatment of Bovine Papillomatosis. Int.J.Curr.Microbiol.App.Sci. 9(05): 119-122. doi: https://doi.org/10.20546/ijcmas.2020.905.012 